Revista Científica do Corpo de Bombeiros Militar de Pernambuco

Artigo publicado no Vol.05 No12 - Edição de JAN a JUN 2019 - ISSN 2359-4829

Versão on-line disponível em: http://www.revistaflammae.com.

\title{
RISCOS SOCIOAMBIENTAIS DOS MANANCIAIS DE ABASTECIMENTO POR ACIDENTES COM TRANSPORTE DE PRODUTOS PERIGOSOS NA BR-277, PARANÁ, BRASIL
}

\section{RESUMO}

Irene Carniatto ${ }^{1}$

Luis Fernando da Rosa Caldeira ${ }^{2}$ Juliana Bento de Oliveira ${ }^{3}$ Wilson Alves de Oliveira ${ }^{4}$

Esta pesquisa foi realizada através do Centro de Ensino, Pesquisa e Extensão em Proteção e Desastres - CEPED Unioeste tendo como foco a importância da BR-277 que é a maior rodovia do estado do Paraná, sendo a responsável pela conexão de Leste e Oeste do Estado, e possui em seu fluxo diário os mais diversos produtos perigosos (PP). Grande parte dos pontos de captação de água para abastecimento público localizam-se próximos à rodovia e são potenciais áreas de risco, pois o abastecimento total de algumas cidades, por vezes, depende de um único manancial, ou nascente situados na área de influência da rodovia. O estudo objetivou relacionar o fluxo de cargas perigosas com os pontos da BR-277, do trecho específico entre Guaraniaçu e Foz do Iguaçu, quais os que mais apresentaram ocorrências de acidentes envolvendo todos os tipos de veículos. Os testes estatísticos indicaram uma fraca correlação entre o fluxo de cargas transportadas e o número de acidentes, e que não existem diferenças significativas quando comparadas as proporções entre as cargas transportadas e os acidentes ocorridos por classes. Os resultados apontaram grande número de acidentes e vítimas envolvendo veículos, e estes se concentraram em áreas de perímetro urbano e de intersecções, justamente próximos dos pontos de intersecção entre a rodovia e os mananciais de abastecimento das cidades estudadas. Foram levantados 23 acidentes com PP e alerta-se para os riscos associados à novos acidentes que envolvam PP, cujos prejuízos são incalculáveis se ocorrer nesses pontos responsáveis pelo abastecimento de água da população local.

Palavras-chave: Modal Rodoviário; Meio Ambiente, proteção da água, acidentes com produtos perigosos, nascentes.

\footnotetext{
${ }^{1}$ Universidade Estadual do Oeste do Paraná - Campus Cascavel, Pesquisadora e Docente do Programa de Pós-Graduação Doutorado e Mestrado em Desenvolvimento Rural Sustentável. E-mail: irenecarniatto@gmail.com.

${ }^{2}$ Universidade Estadual do Oeste do Paraná - Campus Cascavel. Graduando de Ciências Biológicas. Email: luisfernando.rcaldeira@ outlook.com.

3 Universidade Estadual do Oeste do Paraná - Campus Marechal Cândido Rondon. Mestranda do Programa de Pós-Graduação em Desenvolvimento Rural Sustentável,

${ }^{4}$ Universidade Estadual do Oeste do Paraná - Campus Cascavel, Docente do Centro de Ciências Exatas de Tecnológicas.
} 


\title{
SOCIO-ENVIRONMENTAL RISKS TO WATER SOURCES RELATED BY ACCIDENTS WITH TRANSPORT OF DANGEROUS PRODUCTS IN BR-277, PARANÁ, BRAZIL
}

\begin{abstract}
This research was carried out through the Center for Teaching, Research and Extension in Protection and Disasters - CEPED Unioeste, focusing on the importance of BR-277 which is the largest highway in the state of Paraná, being responsible for tracing communication between East and West and is part of your daily flow several dangerous products (PP). The water collection points are located next to the highway, and are potential areas of risk, so that the total supply of some cities sometimes relies on a single source, or spring. The study aimed to connect the dots of the BR-277, specific snippet between Guaraniaçu and Foz do Iguaçu that showed more occurrences of accidents involving all types of vehicles. The statistical tests indicated a weak correlation between the flow of transported loads and the number of accidents, and that there are no significant differences when comparing the proportions between the loads transported and the accidents occurred by classes. The results showed a large number of accidents and victims involving vehicles, and these were concentrated in areas of urban perimeter and intersections, just near the points of intersection between the highway and the water supply sources of the cities studied. A total of 23 accidents involving PP were identified and is alerted to the risks associated with new accidents involving PP a cargo of dangerous product, which are incalculable if it occurs at those points responsible for the water supply of the local population.
\end{abstract}

Keywords: Modal Road, environment, protection of water, accidents with dangerous products, springs.

Artigo Recebido em 28/12/2018 - Aceito em 21/01/2019 - Publicado em 31/03/2019 


\section{INTRODUÇÃO}

A Rodovia BR-277 é uma das principais vias de acesso e escoamento de produtos do Estado do Paraná. A rodovia tem seu início no Porto de Paranaguá e seu término na Ponte da Amizade em Foz do Iguaçu, ponte internacional que divide o Paraná do Paraguai, ela corta todo o Paraná de Leste a Oeste. Sendo caracterizada por um intenso tráfego no modal rodoviário, tanto de veículos de passageiros, quanto de cargas, e dentre eles o transporte de produtos químicos e principalmente combustíveis, que servem de matéria-prima para as indústrias, o que resulta em um considerável risco de impactos socioambientais em caso de acidente rodoviário (CORREA; RAMOS, 2010).

Com a expansão econômica dos países do Mercosul e onde que interconecta com a fronteira do Departamento de Alto Paraná no Paraguai, região que foi considerada pela Organização das Nações Unidas (ONU), como uma das que mais crescerá no mundo nos próximos 20 anos. E esse crescimento já é percebido pela demanda de produtos que tem sido transportados pela BR 277, vindos do Porto de Paranaguá para a região industrial de Cidade de Leste no Paraguai, assim, colaborando com o desenvolvimento regional, com a implantação de indústrias, geração de empregos, exploração do solo para plantações e a utilização dos recursos hídricos para o abastecimento da cidade (ITAIPU, 2017).

Poucos setores aumentaram tanto sua demanda quanto o de materiais e produtos químicos nos últimos anos, aliados a isso tem a crescente expansão dos setores industriais das mais diversificadas áreas, além do aumento da complexidade dos processos produtivos e do volume de produtos, bem como a quantidade em que são transportados e enviados para atender a produção atual (NARDOCCl; LEAL, 2006).

Em 2018, o faturamento líquido estimado para a indústria química brasileira deve fechar em $\mathrm{R} \$ 462,3$ bilhões, com um crescimento de $20,2 \%$ na 
Revista Científica do Corpo de Bombeiros Militar de Pernambuco

Artigo publicado no Vol.05 Nº12 - Edição de JAN a JUN 2019 - ISSN 2359-4829

Versão on-line disponível em: http://www.revistaflammae.com.

comparação com os $R \$ 384,6$ bilhões em 2017, segundo a Associação Brasileira da Indústria Química (Abiquim), em dólares, o faturamento deve crescer 5,4\%, para US $\$ 127,9$ bilhões em 2018 (EM.COM, 2018).

O desempenho da indústria química segundo o guia da Abiquim (2017) vem crescendo ano a ano, com a evolução do faturamento líquido de $2013 \mathrm{~A}$ $2017^{*}$, sendo de $R \$ 315,5$ bilhões em 2013; $R \$ 342,7$ bilhões em 2014; $R \$$ 370,6 bilhões em 2015; R \$ 374,9 bilhões em 2016 e com 384,6 bilhões em 2017. Ainda assim, em alguns meios de comunicações autoridades do segmento afirmam que diante dos indicadores de 2018, o setor de químicos no Brasil teve uma verdadeira década perdida por causa das crises dos últimos anos.

O desempenho da indústria química está diretamente relacionado com o fluxo de cargas dos transportes ocorridos no Paraná e pode ser percebido no transporte dos chamados produtos perigosos.

É denominado produto perigoso, segundo a Resolução ANTT oํ 420/04, para finalidade de transporte, toda substância ou artigo encontrado na natureza ou produzido por qualquer processo que, por suas características físicoquímicas, representa riscos para a saúde das pessoas, para a segurança pública ou para o meio ambiente. É importante que seja feita a distinção do supracitado com as chamadas "cargas perigosas", que são aquelas com dimensões superiores àquelas determinadas no Código de Trânsito Brasileiro, assim como as cargas com estiva ou amarração inadequada (QUEIROZ et al, 2007).

O acidente propriamente dito é um evento ou acontecimento indesejável, que ao ocorrer com veículos em deslocamento, transportando produtos perigosos (PP), demanda o preparo de profissionais capacitados que receberam treinamento, com rigorosas instruções de trabalho e exigências de segurança para atendimento de acidentes esse tipo de transporte. No entanto, pode ainda, provocar danos de gravíssimas proporções de ordem material, pessoal, ao meio ambiente e à infraestrutura viária, caso ocorra acidentes 
(ASSUMPÇÃO, 2012). No momento em que um acidente destes ocorre, uma parcela grande da população sente os efeitos de forma imediata e em longo prazo, devido que os principais recursos biológicos utilizados pela população como solo e água são afetados de forma direta, e a sua contaminação pode interromper as atividades de diversos setores e regiões.

O estudo em questão objetivou diagnosticar os principais pontos de acidentes de maneira geral, buscando encontrar padrões de concentração de acidentes no transporte rodoviário, a fim de compreender o risco de acidentes com produtos perigosos (PP) na rodovia, e elencar os riscos socioambientais atrelados à alguns pontos de captação, situados nos trechos do Município de Guaraniaçu a Foz do Iguaçu, no Paraná, e dessa forma compreender o risco real em uma situação de desastre.

\section{METODOLOGIA}

O estudo em questão baseou-se em uma investigação acerca da logística e da intensidade do fluxo dos deslocamentos de veículos, através do modal rodoviário, no que se refere ao transporte de produtos categorizados como perigosos que são transportados na BR-277 no trecho de Guaraniaçu a Foz do Iguaçu. Foram enfatizados os trechos com maior incidência de acidentes rodoviários e a partir disso, procurou-se analisar o eminente risco que essas áreas estariam vulneráveis, caso ocorra um acidente envolvendo uma carga perigosa.

Desta forma, os pontos amostrados como os relevantes com relação aos acidentes foram também analisados acerca da proximidade com os pontos de captação de água e assim, sendo possível estimar o quanto o manancial que serve de captação para cidade está vulnerável em um eventual acidente que envolva produtos químicos diversos.

O estudo foi possível através dos dados cedidos pelas principais instituições envolvidas no atendimento desses acidentes: Rodovia das 
Cataratas S/A (ECOCATARATAS), 4ํㅡㄴ Grupamento de Bombeiros e 9o Grupamento de Bombeiros do Estado do Paraná. Após o fornecimento dos dados sobre a incidência de acidentes, iniciou-se o estudo estatístico e a caracterização ambiental na busca pelos locais de abastecimento mais próximos destes, a fim de levantar o verdadeiro risco ao qual estão sujeitos. Deste modo, foi realizado um levantamento bibliográfico e também os pontos foram amostrados utilizando o Google Earth Pro (2018).

$\mathrm{Na}$ análise estatística realizou-se o cálculo do Coeficiente de Correlação Linear de Pearson e o teste Qui-quadrado para avaliar a igualdade ou diferença entre duas ou mais proporções, utilizando-se o Software R (www.r-project.org/).

A rodovia 277, a qual o estudo buscou focar a atenção, também já chamada de a "Grande Estrada", que corta o estado do Paraná no sentido Leste-Oeste, ao longo do paralelo $25^{\circ} 30^{\prime}$, ligando o porto de Paranaguá à Curitiba, Guarapuava, Laranjeiras do Sul, Cascavel, Foz do Iguaçu, entre outras cidades que dependem desta rodovia para o escoamento de seus produtos, principalmente o setor agrícola. Ainda, a BR-277 é parte integrante da Rodovia Transversal Panamericana que de Lima, Capital do Peru, atinge Paranaguá (PR) no Atlântico, após atravessar a Bolívia e o Paraguai, com a Rodovia Transparaguaia, que também obedece ao mesmo sentido e possivelmente riscos semelhantes (PARANÁ, 2018).

\section{RESULTADOS E DISCUSSÃO}

O conceito de carga perigosa demonstra que toda e qualquer carga pode tornar-se perigosa, se levadas em consideração suas próprias características, do modo como é transportada ou mesmo pelo comportamento inadequado do profissional que venha a se encarregar do transporte em si (ALMEIDA, 2010). No entanto, as cargas que transportam produtos perigosos, são classificados pela Organização das Nações Unidas (ONU) em nove classes de riscos e respectivas subclasses, se necessário, visando identificar 
facilmente os veículos, a partir de painéis de segurança e rótulos de risco, conforme apresentado na figura 1.

A classificação de uma substância numa das classes de risco, apresentadas na figura 1, é realizada por meio de critérios técnicos, os quais estão definidos na legislação do transporte rodoviário de produtos perigosos.

Uma das principais consequências indesejáveis que acaba tendo suas taxas elevadas com o desenvolvimento econômico e industrial é o aumento da ocorrência de acidentes nas instalações industriais e no transporte dos produtos. Basicamente o planejamento de prevenção dos acidentes com produtos perigosos deve ocorrer nas várias fases do processo, desde a produção, transporte, transformações, utilização e disposição final, mas a maior concentração de riscos encontra-se no transporte e em sua logística (SCHENINI; NEUENFELD; ROSA, 2006).

As políticas para o desenvolvimento econômico adotado pelo país, historicamente, privilegiam o transporte rodoviário de cargas com produtos perigosos em cerca de $70 \%$, enquanto $29 \%$ acabam utilizando o modal ferroviário e apenas $1 \%$, o fluvial.

Figura 1 - Classificação ONU dos Riscos dos Produtos Perigosos.

\begin{tabular}{|c|c|c|}
\hline Classificação & Subclasse & Definições \\
\hline \multirow{7}{*}{ Classe 1} & 1 & Explosivos \\
\hline & 1.1 & Substância e artigos com risco de explosão em massa. \\
\hline & 1.2 & $\begin{array}{l}\text { Substância e artigos com risco de projeção, mas sem risco } \\
\text { de explosão em massa. }\end{array}$ \\
\hline & 1.3 & $\begin{array}{l}\text { Substâncias e artigos com risco de fogo e com pequeno } \\
\text { risco de explosão ou de projeção, ou ambos, mas sem risco } \\
\text { de explosão em massa. }\end{array}$ \\
\hline & 1.4 & Substância e artigos que não apresentam risco significativo. \\
\hline & 1.5 & $\begin{array}{l}\text { Substâncias muito insensíveis, com risco de explosão em } \\
\text { massa; }\end{array}$ \\
\hline & 1.6 & $\begin{array}{l}\text { Artigos extremamente insensíveis, sem risco de explosão } \\
\text { em massa. }\end{array}$ \\
\hline Classe 2 & 2 & Gases \\
\hline
\end{tabular}


Revista FLAMMAE

Revista Científica do Corpo de Bombeiros Militar de Pernambuco

Artigo publicado no Vol.05 Nº12 - Edição de JAN a JUN 2019 - ISSN 2359-4829

Versão on-line disponível em: http://www.revistaflammae.com.

\begin{tabular}{|c|c|c|}
\hline & 2.1 & Gases inflamáveis \\
\hline & 2.2 & Gases não-inflamáveis, não tóxicos. \\
\hline & 2.3 & Gases tóxicos \\
\hline Classe 3 & 3 & $\begin{array}{l}\text { Líquidos inflamáveis: Substâncias que em contato com a } \\
\text { água, emitem gases inflamáveis. }\end{array}$ \\
\hline \multirow{4}{*}{ Classe 4} & 4 & $\begin{array}{l}\text { Sólidos Inflamáveis; Substâncias sujeitas à combustão } \\
\text { espontânea; substâncias que, em contato com água, } \\
\text { emitem gases inflamáveis }\end{array}$ \\
\hline & 4.1 & $\begin{array}{l}\text { Sólidos inflamáveis: substâncias auto-reagentes e } \\
\text { explosivos sólidos insensibilizados. }\end{array}$ \\
\hline & 4.2 & Substâncias inflamáveis, sujeitas à combustão espontânea. \\
\hline & 4.3 & $\begin{array}{l}\text { Substâncias que, em contato com água, emitem gases } \\
\text { inflamáveis: }\end{array}$ \\
\hline \multirow[t]{2}{*}{ Classe 5} & 5 & Substâncias Oxidantes e Peróxidos Orgânicos \\
\hline & 5.1 & Substâncias oxidantes \\
\hline Classe 5 & 5.2 & Peróxidos orgânicos. \\
\hline \multirow{3}{*}{ Classe 6} & 6 & Substâncias tóxicas e Substâncias Infectantes. \\
\hline & 6.1 & Substâncias tóxicas (venenosas). \\
\hline & 6.2 & Substâncias infectantes. \\
\hline Classe 7 & 7 & $\begin{array}{l}\text { Material Radioativo: qualquer material ou substância que } \\
\text { contenha radionuclídeos. }\end{array}$ \\
\hline Classe 8 & 8 & Substâncias corrosivas. \\
\hline Classe 9 & - & Substâncias e Artigos perigosos diversos \\
\hline
\end{tabular}

Fonte: Adaptado de ABIQUIM, 2017 e do Sistema Integrado de Informações para Atendimento de Ocorrências no Transporte de Produtos Perigosos, 2018. Disponível em:

http://200.144.30.103/siipp/public/imprime_classificacao.aspx.

Um dos grandes obstáculos encontrados ao nível das realidades locais é a ausência de informações básicas, que permitam avaliar os impactos desses eventos sobre a saúde humana (expostos, lesionados e óbitos) e o meio ambiente (contaminação de solos, águas superficiais e subterrâneas, ar e cadeia alimentar). As consequências da ausência de dados se refletem diretamente na possibilidade de estimar os custos sociais, ambientais e econômicos desses acidentes e, não obstante, na capacidade de formulação 
Revista Científica do Corpo de Bombeiros Militar de Pernambuco

Artigo publicado no Vol.05 Nº12 - Edição de JAN a JUN 2019 - ISSN 2359-4829

Versão on-line disponível em: http://www.revistaflammae.com.

de políticas públicas de controle e prevenção amplas, adequadas e efetivas no que diz respeito à saúde e ao meio ambiente (ASSUMPÇÃO, 2012).

No levantamento documental realizado dos dados oferecidos pela Rodovia das Cataratas S/A (ECOCATARATAS, 2017), 4ํ Grupamento de Bombeiros e $9^{\circ}$ Grupamento de Bombeiros do Estado do Paraná foi possível através do estudo dos dados a visualização do fluxo de cargas na BR 277 no trecho de estudo e também sua organização por classes (Figura 2).

FIGURA 2. Fluxo de Cargas de Produtos Perigosos de 2013 a 2017, de Guaraniaçu a Foz do Iguaçu (KM 535 a 725 da BR 277), segundo as suas Classes de Risco.

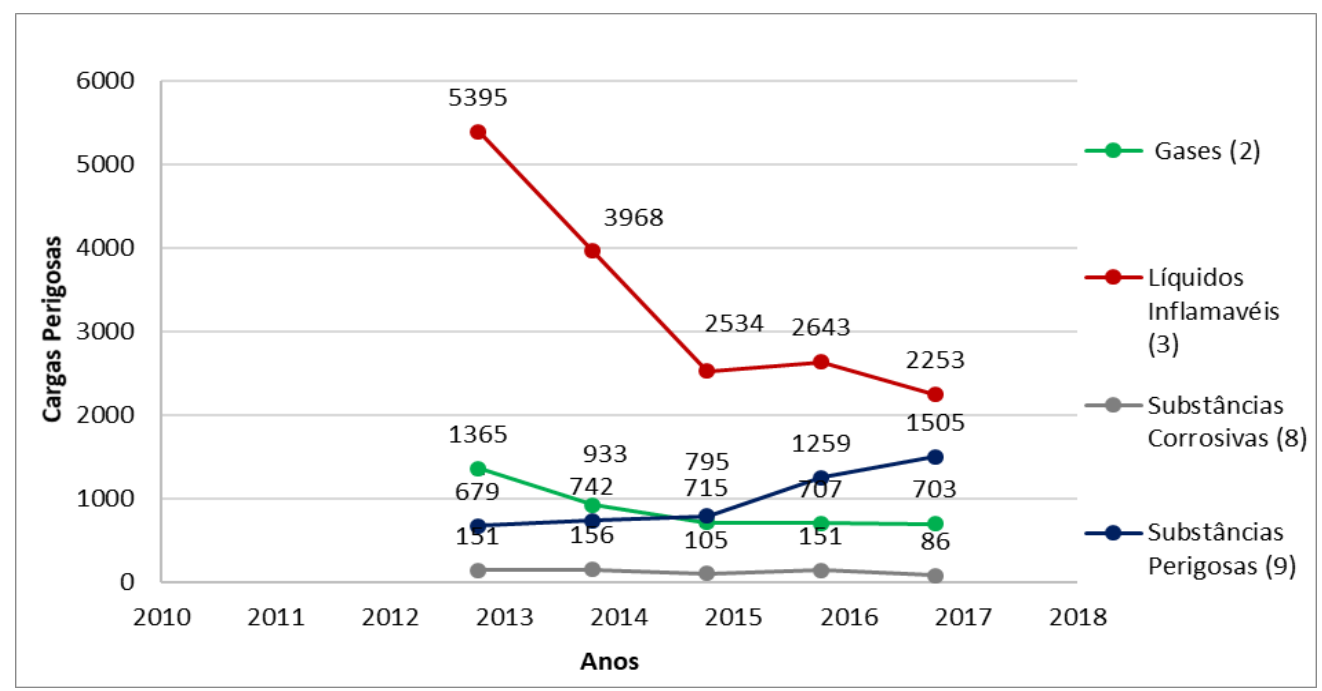

Fonte: Os autores.

Os dados registram o número de veículos de cargas com produtos perigosos registrado nas registrado nas três praças de pedágio que a concessionária possui no trecho, e os mesmos revelam que no ano de 2013 os totais foram maiores para as classes dos líquidos inflamáveis e gases, vindo diminuindo seus valores de 2014 até 2017 (Figura 2). No entanto, a experiência dos gestores e dos pesquisadores é de que nos últimos cinco anos o fluxo de veículos tem aumentado ano a ano, inclusive o transporte de cargas.

Tal fenômeno se explica pois que de 2013 a 2014 foram instalados os dispositivos de pedágio de pagamento automático, e ano a ano é maior 0 
Revista Científica do Corpo de Bombeiros Militar de Pernambuco

Artigo publicado no Vol.05 Nº12 - Edição de JAN a JUN 2019 - ISSN 2359-4829

Versão on-line disponível em: http://www.revistaflammae.com.

número de veículo de transporte de cargas que usam esses dispositivos a fim de ganhar tempo e agilizar sua passagem nos pedágios. No entanto, nessas cancelas automáticas não é feito o registro do veículo e a sua carga, sendo apenas registrado o valor monetário de sua passagem no pedágio.

Esse tipo de falha no sistema, em registrar a placa, descrição e tipos de cargas que carregam, gera uma subnotificação do número de veículos e, portanto, o número real de caminhões é bem maior.

$\mathrm{Na}$ tabela 1 é possível estabelecer relações entre o fluxo de cargas de produtos perigosos com os acidentes ocorridos no mesmo período, e mesmo trecho, segundo as suas classes.

TABELA 1 - Fluxo de Cargas e Acidentes com Produtos Perigosos de 2013 a 2017, de Guaraniaçu a Foz do Iguaçu (KM 535 a 725 da BR 277), segundo as suas Classes de Risco.

\begin{tabular}{lrrrrrr}
\hline \multicolumn{1}{c}{$\begin{array}{c}\text { Classes das cargas } \\
\text { transportadas }\end{array}$} & $\mathbf{2 0 1 3}$ & $\mathbf{2 0 1 4}$ & $\mathbf{2 0 1 5}$ & $\mathbf{2 0 1 6}$ & $\mathbf{2 0 1 7}^{\text {* }}$ & total \\
\hline Classe 3 - Liquídos inflamáveis & 5395 & 3968 & 2534 & 2643 & 2253 & 16793 \\
Classe 9 - Substâncias perigosas & 679 & 742 & 795 & 1259 & 1505 & 4980 \\
Classr 2 - Gases & 1365 & 933 & 715 & 707 & 703 & 4423 \\
Classe 8 - Substâncias & & & & & & \\
corrosivas & 151 & 156 & 105 & 151 & 86 & 649 \\
classe "Outras" & 98 & 97 & 75 & 112 & 274 & 656 \\
\hline Total & 7590 & 5799 & 4149 & 4760 & 4547 & 27501 \\
\hline Acidentes por ano & 2 & 3 & 0 & 0 & 3 & 8 \\
\hline
\end{tabular}

* Obs: Total parcial até setembro em 2017.

Fonte: Os autores.

A classe 3 que se refere aos líquidos inflamáveis (gasolina, etanol e óleo diesel) teve uma maior quantidade de cargas transportadas nos cincos anos, com um total de 16.793 cargas perigosas, seguido pela Classe 9 (Substâncias perigosas) com 4.980 cargas transportadas e a Classe 2 (Gases) com 4.423 cargas.

Buscando analisar estatisticamente os dados da Tabela 1, foi realizado o cálculo do coeficiente de correlação linear de Pearson entre o total do fluxo por ano e o número de acidentes, cujo valor foi 0,3892. Este resultado indica uma fraca correlação linear entre as variáveis analisadas. 
Foi realizado, também, um teste Qui-quadrado para verificar se existe diferença significativa entre as proporções dos totais das classes e o número de acidentes registrados, no mesmo período, com 95\% de confiança. Pode-se observar que entre as categorias 1 (Líquidos Inflamáveis), categoria 2 (Substâncias perigosas), categoria 3 (Gases) e a categoria 4 (Substâncias corrosivas) não existe diferença significativa entre as proporções por classe. Havendo diferença significativa quando comparada as categorias 1, 2, 3 respectivamente com a categoria 5, denominada como Classe "Outras", conforme tabela 2.

TABELA 2 - Teste Comparativo das Proporções de Fluxo Total de Cargas e Acidentes com Produtos Perigosos de 2013 a 2017, de Guaraniaçu a Foz do Iguaçu (KM 535 a 725 da BR 277), segundo as suas Classes de Risco.

\begin{tabular}{clccrc}
\hline Categoria & \multicolumn{1}{c}{ Descrição } & Total & $\begin{array}{c}\text { Totais de } \\
\text { Acidentes }\end{array}$ & $\begin{array}{c}\text { Teste } \\
\text { Qui-quadrado }\end{array}$ & p-value \\
\hline 1 & Classe 3 - Liquídos inflamáveis & 16793 & 4 & $1 \times 5=$ & 0,006225 \\
\hline 2 & Classe 9 - Substâncias perigosas & 4980 & 1 & $2 \times 5=$ & 0,03823 \\
\hline 3 & Classe 2 - Gases & 4423 & 0 & $3 \times 5=$ & 0,008832 \\
\hline 4 & Classe 8 - Substâncias corrosivas & 649 & 1 & $4 \times 5=$ & 1 \\
\hline 5 & Classe "Outras" & 656 & 2 & & \\
\hline
\end{tabular}

Fonte: Os autores.

Os dados analisados são os disponíveis, que se conseguiu obter dos órgãos oficiais, ainda que não reflitam na totalidade o fluxo intenso de veículos nesta região, conforme justificado acima, demonstram que existem muitas variáveis presentes no número de acidentes em uma rodovia e o possível risco à vida, à saúde a ao ambiente. $O$ teste revela que não existe uma correlação linear entre o aumento de fluxo e aumento de acidentes. Existe uma tendência natural que isso aconteça, mas muitos outros fatores determinam as condições para que 0 acidente ocorra.

$\mathrm{Na}$ tabela 3 apresenta-se o número de acidentes no intervalo de 5 anos, totalizados e disponibilizados, bem como o grande número de feridos e mortos em decorrência dos mesmos. 
TABELA 3 - Número de Acidentes, Feridos e Vítimas Fatais, de 2012 a 2016, de Guaraniaçu a Foz do Iguaçu.

\begin{tabular}{|l|c|c|c|}
\hline Ano & $\begin{array}{c}\text { Número de } \\
\text { acidentes }\end{array}$ & № feridos & № mortes \\
\hline 2012 & 1828 & 809 & 71 \\
\hline 2013 & 1715 & 711 & 59 \\
\hline 2014 & 1688 & 730 & 54 \\
\hline 2015 & 1352 & 575 & 48 \\
\hline 2016 & 1386 & 612 & 49 \\
\hline Total & 7969 & 3437 & 281 \\
\hline
\end{tabular}

Fonte: Os autores.

Observa-se na Tabela 3, um alto número de vítimas com 3.437 feridos, e que a cada 2 acidentes houve 1 ferido e um total de vítimas fatais de 281 pessoas, em 5 anos na região de Guaraniaçu a Foz do Iguaçu. A esse número podem ser somadas as vítimas que são atendidas como feridas, mas depois por complicações vem a óbito nos hospitais.

Dentre os motivos registrados dos acidentes, destacam-se a falta de atenção, velocidade incompatível, ingestão de álcool, não guardar distância de segurança, defeito mecânico em veículo, desobediência à sinalização, dormindo, ultrapassagem indevida, animais na pista, defeito na via, e outras.

Os acidentes sempre são danosos e ainda, especialmente quando envolvem os caminhões e carretas no transporte de produtos perigosos podem ter consequências catastróficas, sobretudo diante da proximidade de cidades e de populações lindeiras às principais rodovias, além das perdas humanas, do risco social atrelado e os custos decorrentes da contaminação ambiental (SANTOS; RIBEIRO, 2014).

Nesse sentido, foram analisados quais são os pontos com a maior incidência de acidentes, além da localização, e o quilômetro (km) onde o 
Revista Científica do Corpo de Bombeiros Militar de Pernambuco

Artigo publicado no Vol.05 Nº12 - Edição de JAN a JUN 2019 - ISSN 2359-4829

Versão on-line disponível em: http://www.revistaflammae.com.

acidente ocorreu, as características dos locais e o número de ocorrências (Tabela 4).

TABELA 4 - Pontos com Maior Incidência de Acidentes na BR-277, de Guaraniaçu a Foz do Iguaçu, em 2011.

\begin{tabular}{|c|c|c|c|c|}
\hline Ord. & Localização & Rodovia/Km & $\begin{array}{c}\text { Característica do } \\
\text { Local }\end{array}$ & $\begin{array}{l}\text { Quantidade de } \\
\text { acidentes em } \\
2011 \\
\end{array}$ \\
\hline 1 & $\begin{array}{l}\text { Lat. } 24^{\circ} 57^{\prime} 51.93^{\prime \prime} \mathrm{S} \\
\text { Long. } 53^{\circ} 24^{\prime} 23.90^{\prime \prime} \mathrm{O}\end{array}$ & BR277/584 & $\begin{array}{c}\text { Trevo Cataratas - } \\
\text { Cascavel }\end{array}$ & 107 \\
\hline 2 & $\begin{array}{l}\text { Lat. } 24^{\circ} 58^{\prime} 00.06 " S \\
\text { Long. } 53^{\circ} 25^{\prime} 27.65^{\prime \prime} \mathrm{O}\end{array}$ & BR277/586 & $\begin{array}{c}\text { Trevo Portal - } \\
\text { Cascavel }\end{array}$ & 49 \\
\hline 3 & $\begin{array}{l}\text { Lat. } 25^{\circ} 14^{\prime} 34.28 " \mathrm{~S} \\
\text { Long. } 53^{\circ} 58^{\prime} 31.19^{\prime \prime} \mathrm{O}\end{array}$ & BR277/657 & $\begin{array}{l}\text { Trevo Perímetro } \\
\text { Urbano de } \\
\text { Matelândia }\end{array}$ & 45 \\
\hline 4 & $\begin{array}{l}\text { Lat. } 25^{\circ} 29^{\prime} 56.06^{\prime \prime} \mathrm{S} \\
\text { Long. } 54^{\circ} 31^{\prime} 48.322^{\prime \prime}\end{array}$ & BR277/723 & $\begin{array}{c}\text { Retorno - Foz do } \\
\text { Iguaçu }\end{array}$ & 48 \\
\hline \multirow[t]{2}{*}{5} & $\begin{array}{l}\text { Lat. } 25^{\circ} 30^{\prime} 39.01^{\prime \prime} \mathrm{S} \\
\text { Long. } 54^{\circ} 33^{\prime} 03.766^{\prime \prime}\end{array}$ & BR277/725 & $\begin{array}{c}\text { Trevo Costa e } \\
\text { Silva - Foz do } \\
\text { Iguaçu }\end{array}$ & 53 \\
\hline & Total & & & 302 \\
\hline
\end{tabular}

Fonte: Rodovia das Cataratas S/A (ECOCATARATAS), 2017.

Para melhor compreensão do território geográfico foram localizados os pontos de maiores índices de acidentes, usando o Google Earth (2017), nos pontos geoprocessados (Figura 3). 
Revista Científica do Corpo de Bombeiros Militar de Pernambuco

Artigo publicado no Vol.05 º12 - Edição de JAN a JUN 2019 - ISSN 2359-4829

Versão on-line disponível em: http://www.revistaflammae.com.

FIGURA 3 - Mapa dos Pontos de Maior Incidência de Acidentes na BR-277, de Guaraniaçu a Foz do Iguaçu.

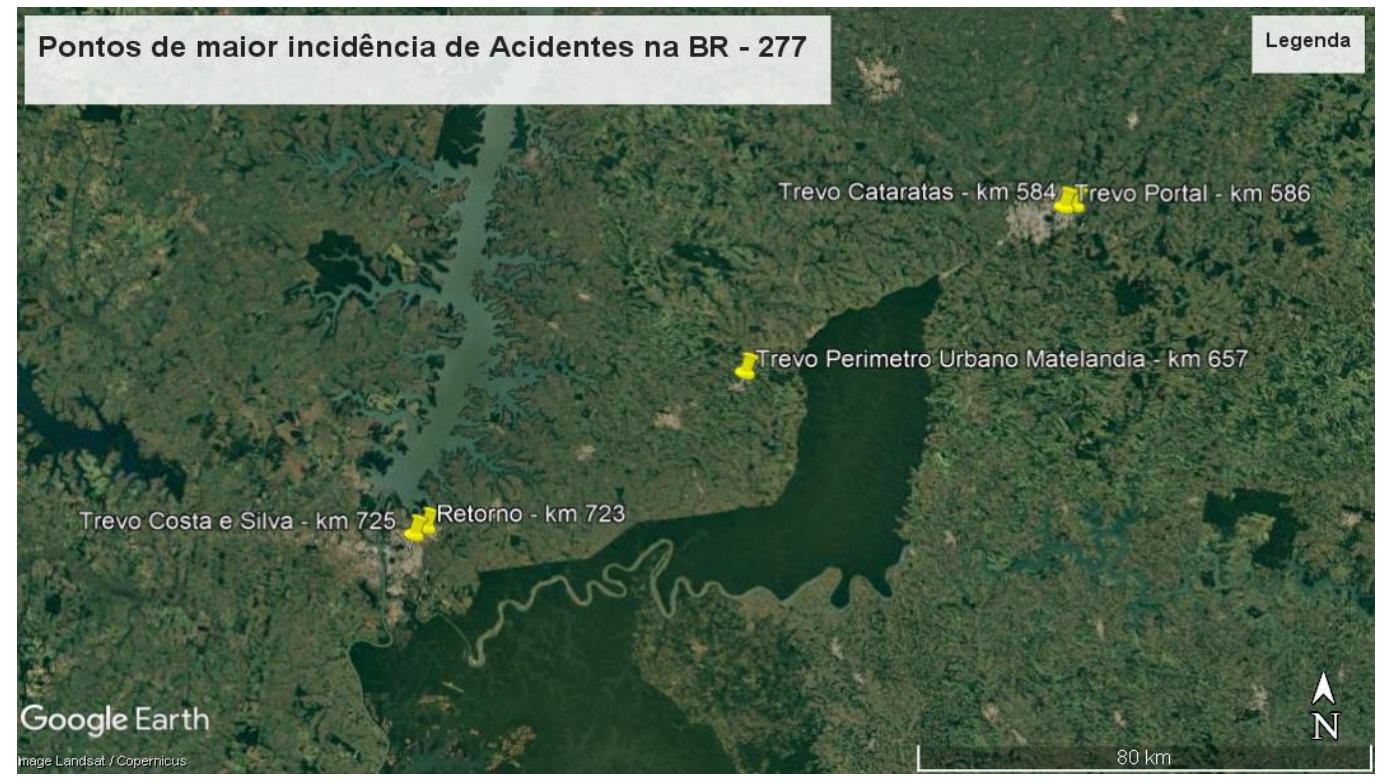

Fonte: Google Earth Pro, 2017.

Ao cruzarmos os dados dos locais com as maiores taxas de acidente ao longo da BR-277, com os pontos de abastecimento das cidades próximas, foi possível observar o risco real que estes locais estão submetidos, já que em eventual acidente com "TRPP", grande partes das cidades em questão seriam afetadas, devido que o produto perigoso entraria em contato com pontos de abastecimento da cidade, e sendo assim a população ficaria sem acesso a água potável.

Desta maneira, há um agravante no fato de muitas cidades menores dependerem exclusivamente de apenas um manancial para manter suas atividades diárias, ou seja, em casos de contaminação severa do manancial, em decorrência de um acidente com uma carga perigosa, o maior prejuízo recaí sobre o aspecto socioambiental, o que se torna extremamente grave e incalculável.

Vilas Boas (2003) ressalta que os mananciais que se localizam próximos à rodovia, tem facilidade para captar o produto químico que porventura venha a vazar da carga e dificultando ações mitigatórias, além do que, dependo do 
conteúdo do produto e das condições do ambiente, pode entrar rapidamente em contato com o curso hídrico. Assim, os impactos socioambientais podem atingir as regiões povoadas, através da contaminação dos seus mananciais de abastecimento público, afetando o nicho e os moradores a sua volta.

Segundo Carniatto (2007, apud SANTOS, 2001), a qualidade das águas está permanentemente ameaçada por dois grupos principais de riscos: "a contaminação por microrganismos patogênicos e a modificação das características físicas e químicas dos corpos d'água". Assim sendo, "em função da natureza do solo de onde são originárias, das condições climáticas e do grau de poluição que lhes é conferido". Portanto, tendo em vista que variam as altas quantidades e a natureza dos constituintes presentes na água, em caos de um acidente com PP, por consequência, sofreria uma severa contaminação das águas superficiais $\mathrm{e}$, ainda, pode-se agravar o problema com a contaminação do lençol freático, que é de difícil descontaminação.

Neste caso, a função de descarga na microbacia hidrográfica tem o seu comportamento alterado devido às modificações abruptas ocorridas em caso de derramamento de PP, afetando diretamente sua capacidade de captação e armazenagem, bem como as práticas de manejo que possam ser utilizadas para a restauração dessas; assim, "há uma alteração na função química e de habitat pela alteração do escoamento no tempo e uma maior quantidade de materiais carreados, causando impactos na flora e fauna aquática, na rede de drenagem e na saúde do ecossistema". A autora registra que as bacias hidrográficas consideradas de pequeno tamanho, geralmente denominadas de microbacias hidrográficas, "apresentam maior sensibilidade de resposta em decorrência da pouca capacidade de tamponamento de sua rede de drenagem, menor tempo de permanência da água, assim como menor heterogeneidade de ambientes", segundo Carniatto (2007) citando Zakia (1998), Hewlett; Nutter (1969); Whitehead; Robinson (1993), Azevedo Neto; Alvarez (1982), dentre outros. 
Existem muitos casos de rodovias que passam dentro do perímetro urbano de cidades, sendo que na ocorrência de algum acidente dentro desse perímetro envolvendo tais produtos perigosos, podem ocasionar efeitos de grandiosas proporções para os moradores locais. Geralmente os acidentes que envolvam "PP" em áreas urbanas, densamente povoadas, constituem-se em situações complexas, pelos danos possíveis sobre a população residente ou de passagem. Quando existe derramamento de produtos químicos perigosos nesses trechos, a sua absorção pelo solo é difícil, devido às superfícies serem pavimentadas, o que aumenta o risco de contaminação de pessoas no entorno da área do acidente (VERGINASSI et al, 2007).

No caso do município de Cascavel, o mesmo apresenta sua bacia hidrográfica de captação de água inserida dentro do perímetro urbano e cruzando a rodovia, aumentando assim a probabilidade de poluição por produtos perigosos, principalmente em caso de acidentes.

De acordo com a Agência Nacional das Águas (ANA, 2017), o ponto 1 referido na figura 4 , é responsável pelo abastecimento de até $45 \%$ da cidade de Cascavel no Paraná, com uma população de 286.205 habitantes (IBGE, 2010), ou seja, este manancial é o responsável por cerca de 128.792 pessoas que teriam seu acesso à água potável comprometido.

FIGURA 4 - Mananciais Próximos aos Trechos de Maior Risco.

\begin{tabular}{|c|c|c|c|c|}
\hline Ord. & $\begin{array}{l}\text { Nome/Cidade } \\
\text { de Referência }\end{array}$ & Início & Final & Rodovia/Km \\
\hline 1 & $\begin{array}{l}\text { Rio Cascavel, } \\
\text { Cascavel - PR }\end{array}$ & $\begin{array}{l}\text { Lat. } 24^{\circ} 57^{\prime} 50.85^{\prime \prime S} \\
\text { Long. } 53^{\circ} 24^{\prime} 42.70^{\prime \prime} \mathrm{O}\end{array}$ & $\begin{array}{l}\text { Lat. } 24^{\circ} 58^{\prime} 00.06^{\prime \prime} \mathrm{S} \\
\text { Long. } 53^{\circ} 25^{\prime} 27.65^{\prime \prime} \mathrm{O}\end{array}$ & $\begin{array}{c}\text { BR 277/ 585 AO } \\
\text { KM 586.500 }\end{array}$ \\
\hline 2 & $\begin{array}{c}\text { Rio Alegria, } \\
\text { Medianeira - PR }\end{array}$ & $\begin{array}{l}\text { Lat. } 25^{\circ} 17^{\prime} 11.67^{\prime \prime S} \\
\text { Long. } 54^{\circ} 32^{\prime} 18^{\prime \prime O}\end{array}$ & $\begin{array}{c}\text { Lat. } 25^{\circ} 17^{\prime} 9.92 " \mathrm{~S} \\
\text { Long. } 54^{\circ} 5^{\prime} 34.16^{\prime \prime} \mathrm{O}\end{array}$ & $\begin{array}{c}\text { BR } 277 \text { (Perímetro } \\
\text { urbano) }\end{array}$ \\
\hline 3 & $\begin{array}{l}\text { Rio Tamanduá, } \\
\text { Foz do Iguaçu }\end{array}$ & $\begin{array}{l}\text { Lat. } 25^{\circ} 28^{\prime} 49.37^{\prime \prime S} \\
\text { Long. } 54^{\circ} 29^{\prime} 10.00^{\prime \prime O}\end{array}$ & $\begin{array}{l}\text { Lat. } 25^{\circ} 29^{\prime} 12.63^{\prime \prime} \mathrm{S} \\
\text { Long. } 54^{\circ} 30^{\prime} 4.64^{\prime \prime} \mathrm{O}\end{array}$ & $\begin{array}{c}\text { BR } 277 \text { (Perímetro } \\
\text { urbano) }\end{array}$ \\
\hline
\end{tabular}

Fonte: Rodovia das Cataratas S/A (ECOCATARATAS), 2017.

Já no ponto 2, o Rio Alegria localiza-se próximo do perímetro urbano de Medianeira - PR, de maneira que o abastecimento da cidade ocorre hoje em sua totalidade por este rio, fornecendo água para aproximadamente 33.768 
habitantes. Um eventual acidente comprometeria toda a população local, gerando problemas de abastecimento catastróficos, aliado ao fato do Atlas da Agência Nacional das Águas (ANA) já categorizar a situação como crítica, devida ao aumento da demanda e requerer a exploração de novos mananciais para a cidade de Medianeira.

O ponto 3, o Rio Tamanduá, pertencente à cidade de Foz do Iguaçu, é o responsável pelo abastecimento de $34 \%$ da população, um total de cerca de 105.027 (IBGE, 2010) de pessoas, que provavelmente sofreriam a falta de acesso à água em decorrência do vazamento de qualquer tipo de produto, além dos efeitos secundário e até acumulativos de alguns dos químicos frequentemente transportados.

Contudo, as situações particulares de cada produto necessitam, no caso de um eventual acidente, certo nível de capacitação e especialização para o pronto atendimento e adoção dos procedimentos de segurança no momento do ocorrido. Dessa forma, apesar de indispensável, o envolvimento dos órgãos governamentais de segurança não é suficiente para diminuir os efeitos da ocorrência de qualquer tipo de acidente com produtos perigosos nas rodovias, tornando a empresa proprietária do material transportado e a transportadora as principais responsáveis pelas medidas corretivas e preventivas (SANTOS; RIBEIRO, 2014).

Os dados analisados mostram a vulnerabilidade dos mananciais e das populações que deles dependem para sua sobrevivência. E, portanto, questiona-se em que medidas o gerenciamento desses recursos hídricos tem sido eficaz nesses municípios? Que atitudes, ações e planejamento deveriam ser executados e como deveriam ser decididos?

O gerenciamento das bacias hidrográficas é uma ação territorial cuja área de influência se encontra numa escala considerada como grande. "Seus usos múltiplos devem ser compatibilizados e negociados juntamente com a manutenção do equilíbrio dos ecossistemas e da qualidade da água enquanto bem vital, com destaque especial para alguns fatores". Declara que, o 
"conceito de gerenciamento integrado é de vital importância e os componentes não estão somente no processo de gerenciamento do ciclo, mas são mutuamente interativos". "Como as microbacias são contributivas e constituintes das grandes bacias, os mesmos fatores não visualizados em escala micro, mas, diretamente influenciados pelas respostas, usos e qualidade presentes nas microbacias" (BRASIL, 2004 apud CARNIATTO, 2007, p.52).

O gerenciamento, conservação e melhoria ambiental têm por objetivo a integração entre as atividades humanas e o ambiente natural, e estes são essenciais para a implementação de projetos e os atendimentos aos diversos usos da água, que exigem descentralização e participação da sociedade civil local, segundo Carniatto (2007, p.52),

Nas micro e grandes bacias hidrográficas, sem perder de vista 0 entendimento de que tais aspectos constituem peculiaridades locais, pois exigem descentralização das decisões e crescente envolvimento da sociedade civil no seu planejamento e implementação.

A descentralização da participação está prevista na Lei № 9.433/97, através dos Comitês de Bacias Hidrográficas, "nos quais a sociedade civil tem a possibilidade de atuar com maior eficiência e autoridade, uma vez que esses são consultivos e deliberativos" (CARNIATTO, 2007, p. 52).

Ainda a autora esclarece que, "a noção de Gestão Integrada dos Recursos Hídricos assume várias dimensões e envolve conotações diversas que contaram com o apoio gradual e consensual de cientistas, administradores públicos e empresariais, além de associações técnico-científicas"; segundo Machado (2003) citado por Carniatto (2007, p. 52 e 53),

Trata-se de uma integração, primeiramente, no sentido de abranger os processos do ciclo hidrológico; em segundo lugar, com relação aos usos múltiplos de um corpo hídrico; em terceiro lugar, no que diz respeito ao inter-relacionamento dos corpos hídricos com os demais elementos dos mosaicos de ecossistemas (solo, fauna e flora); em quarto lugar, em termos de coparticipação entre gestores, usuários e populações locais no planejamento e na administração dos recursos hídricos; e, finalmente, em relação aos anseios da sociedade por um 
desenvolvimento socioeconômico com preservação ambiental, na perspectiva da criação de sociedades sustentáveis.

Propondo o aspecto democrático do gerenciamento das águas "evidencia uma maior participação da coletividade nas instituições públicas para a adoção de medidas visando efetivar a proteção dos recursos hídricos" (CARNIATTO, 2007, p.52).

\section{CONCLUSÃO}

O presente estudo mostra que grande parte dos acidentes registrados na BR-277 foram em locais de perímetro urbano, com grande concentração de população envolvida nos entornos e de grande fluxo de veículos. O fato de muitos acidentes não envolverem uma carga de "PP" pode ser meramente uma questão de circunstância, visto o elevado número de acidentes nos locais, aliado ao fato do grande fluxo de veículos transportando produtos com iminente risco à população.

Os testes estatísticos mostraram uma fraca correlação entre o fluxo de cargas transportadas e o número de acidentes, apontando que outras variáveis estão presentes ao determinar o grande número de acidentes e vítimas, necessitando aprofundamento e novos estudos neste tema.

Em grande parte, a melhoria no setor depende muito do investimento privado e pelas concessões das rodovias. Entretanto, outras ações podem e devem ser objetos de estudo, como a preparação da mão-de-obra, investimento por parte do governo em infraestrutura, condições viáveis e um forte programa de Educação Ambiental, para que a prevenção seja a melhor ferramenta na segurança do transporte com químicos.

É necessário que sejam feitos estudos da situação atual de outras rodovias e de práticas objetivadas pelo governo e empresas para a real melhoria das condições de tráfego de "PP" e dessa forma a preservação ambiental. 
Outro ponto que necessita ser debatido é o gerenciamento participativo, com a efetiva participação social das instituições, bem como o estudo aprofundado para a utilização em outros modais de transportes, como o ferroviário aqui em nossa região Oeste do Paraná, e também o modal hidroviário pode ser apontado como mais seguros para que possam fazer 0 escoamento destes produtos.

O CEPED Unioeste continua avançando em estudos que busquem dados e indicadores que possam tornar nosso território menos vulnerável, próspero e resiliente. Nesse sentido desenvolve pesquisa e capacitação de técnicos, gestores e da comunidade em temas como a preservação da água, comunidades sustentáveis, mudanças climáticas e cidades resilientes.

\title{
Agradecimentos
}

Os autores agradecem ao Centro de Ensino, Pesquisa e Extensão em Proteção e Desastres CEPED UNIOESTE pela oportunidade para o desenvolvimento da pesquisa, à Companhia de Saneamento do Paraná SANEPAR pelo financiamento, ao apoio do Centro Universitário de Estudos e Pesquisas sobre Desastres - CEPED/PR e REDESASTRE, à Fundação de Apoio ao Desenvolvimento da Faculdade Estadual de Filosofia, Ciências e Letras de Paranaguá da Universidade Estadual do Paraná - FUNESPAR, e à Ecocataratas S/A.

\section{REFERÊNCIAS BIBLIOGRÁFICAS}

\author{
ANA. AGÊNCIA NACIONAL DAS ÁGUAS, 2017. Acesso à Informação. \\ Disponível \\ em:<http://www2.ana.gov.br/Paginas/acessoainformacao/default.asp $x>$ Acesso \\ em: 10/10/2017.
}


Revista Científica do Corpo de Bombeiros Militar de Pernambuco

Artigo publicado no Vol.05 º12 - Edição de JAN a JUN 2019 - ISSN 2359-4829

Versão on-line disponível em: http://www.revistaflammae.com.

ALMEIDA, P. C. Acidentes ambientais gerados no transporte rodoviário de produtos perigosos. Monografia apresentada ao Curso de Pós-Graduação em gestão ambiental e ecologia da Universidade Estadual de Montes Claros, 2010.

ABIQUIM. Associação Brasileira Da Indústria Química, 2017. Disponível em: < https://abiquim.org.br/uploads/guias.../desempenho_industria_quimica_2017.pd f>. Acesso em: 10/10/2017.

ASSUMPÇÃO, E. E. Acidente de transporte de carga de produto perigoso em rodovia tendo como causa principal o motorista/condutor. Monografia apresentada para o título de Especialista no curso de Pós-graduação em engenharia de segurança do trabalho, Universidade Tecnológica Federal do Paraná, 2012.

BRASIL. Ministério do Meio Ambiente do Brasil - MMA. Navegando pelas Águas. Plano Diretor para a utilização dos recursos hídricos do Estado do Paraná - Relatório Setorial - Volume K. Disponível:

http://www.hidricos.mg.gov.br/ufparana/volumek/ cap2.htm Acesso: 20/09/2004.

CARNIATTO, Irene. Subsídios para um Processo de Gestão de Recursos Hídricos e Educação Ambiental nas Sub-Bacias Xaxim e Santa Rosa, Bacia Hidrográfica Paraná III. 2007. 278p. (Tese) Doutorado em Ciências Florestais. Programa de Pós-Graduação em Engenharia Florestal, Setor de Ciências Agrárias da Universidade Federal do Paraná. CURITIBA, 2007.

ECOCATARATAS. Rodovia das Cataratas S/A. Relatório de dados, 2017. Impresso.

EM.COM.BR - ECONOMIA. Estimativa de faturamento líquido do setor em 2018 é de $R \$ 462,3$ bi, diz Abiquim. 07/12/2018. Disponível em:

https://www.em.com.br/app/noticia/economia/2018/12/07/internas_economia,10 11404/estimativa-de-faturamento-liquido-do-setor-em-2018-e-de-r-462-3-bid.shtml

ITAIPU. Mais Energia para Integrar e Desenvolver o Brasil e o Paraguai. 09/01/2017. Disponível em: https://www.itaipu.gov.br/sala-deimprensa/positionpapers/mais-energia-para-integrar-e-desenvolver-o-brasil-e-oparaguai.

CORREA, V. H. C; RAMOS, P. A precariedade do transporte rodoviário brasileiro para o escoamento da produção de soja do Centro-Oeste: situação e perspectivas. Rev. Econ. Sociol. Rural, Brasília, v. 48, n. 2, p. 447-472, 2010. 
Revista Científica do Corpo de Bombeiros Militar de Pernambuco

Artigo publicado no Vol.05 Nº12 - Edição de JAN a JUN 2019 - ISSN 2359-4829

Versão on-line disponível em: http://www.revistaflammae.com.

GOOGLE EARTH-MAPAS PRO. Http://mapas.google.com. Consulta realizada em 2017 e 2018.

IBGE. Instituto Brasileiro de Geografia e Estatística. População. 2010.

Disponível em: <https://www.ibge.gov.br/estatisticas-novoportal/sociais/ populacao.html>. Acesso em: data 10/10/2017.

MACHADO, Carlos José Saldanha. Recursos Hídricos e Cidadania no Brasil: limites, alternativas e desafios. Ambiente; sociedade Ambient. soc. vol. 6 n.2, Campinas July/Dec.2003.

NARDOCCI, A. C.; LEAL, O. L. Informações sobre acidentes com transporte rodoviário de produtos perigosos no Estado de São Paulo: os desafios para a Vigilância em Saúde Ambiental. Saúde e Sociedade, São Paulo, v. 15, n. 2, p. 113-121, 2006.

OLIVEIRA, José Roberto Guedes de; ALVES, Valdir Aparecido. Meio Ambiente Natural. Disponível: http://www.cnrhsrh.gov.br/artigos/mambientenat guedes.htm. 2002.

PARANÁ. DER. Departamento de Estradas de Rodagem. BR-277 - Curitiba Cascavel - Foz do Iguaçu. Disponível em:

http://www.der.pr.gov.br/modules/conteudo/conteudo.php?conteudo=15.

Acesso em: dez. 2018.

QUEIROZ, M. T. A; SILVA, A. R; FLORÊNCIO, I. de S; SILVA, R. R;

PERPÉTUO, T. M. C. Acidentes no transporte de cargas/produtos perigosos no colar metropolitano do vale do ao, Minas Gerais. SEGeT - Simpósio de Excelência em Gestão e Tecnologia. Jornal Vale do Aço, Minas Gerais, 13 de abril de 2007.

SANTOS, Juscelino Batista dos. Impacto Ambiental do Aterro Controlado da Cidade de Manaus, sobre os recursos hídricos da sua área de influência direta. 2001. 1v. 88p. Mestrado. Universidade do Amazonas - Ciências do Ambiente e Sustentabilidade na Amazônia. Manaus - AM, 2001.

SANTOS, R. C; RIBEIRO S. O transporte rodoviário de cargas perigosas e suas exigências. 2014.

SCHENINI, P. C; NEUENFELD, D. R; ROSA, A. L. M. O gerenciamento de riscos no transporte de produtos perigosos. XIII SIMPEP, Simpósio de engenharia de produção, 2006. 
VERGINASSI, A; DORES, E. F. G. de C; WEBER, O. L. dos S; LAMBERT, J. A. Acidentes ambientais no transporte rodoviário de cargas perigosas no estado de Mato Grosso. Engenharia Ambiental, v.4, n.1, p. 103-119, 2007.

VILAS BOAS, A. Movimentação rodoviária de produtos perigosos em Mato Grosso e suas consequências ao homem e ao ambiente. 2003. 75 p. Curso de Especialização em Engenharia de Segurança do Trabalho - Faculdade de Engenharia e Tecnologia, Universidade Federal de Mato Grosso. 2003. 